\title{
Theoretical Nonlinear Optics Equivalence Between Mesoionic and Polyenic Bridges in Push-Pull Compounds
}

\author{
Andréa M. S. Silva ${ }^{a}$, Gerd Bruno da Rocha ${ }^{a}$, Paulo Henrique Menezes ${ }^{a}$, Joseph Miller ${ }^{b}$ and \\ Alfredo M. Simas $*$, a \\ ${ }^{a}$ Departamento de Química Fundamental, Universidade Federal de Pernambuco, 50670-901 Recife - PE, Brazil \\ ${ }^{b}$ Departamento de Química, Universidade Federal da Paraíba, 58051-970 João Pessoa - PB, Brazil
}

\begin{abstract}
Nesse trabalho, descrevemos uma investigação semi-empírica com o objetivo de estabelecer uma equivalência em termos do valor da primeira hiperpolarizabilidade estática, $\beta(0)$, de compostos push-pull do tipo aceitador de elétrons(A)-ponte-doador de elétrons(D) formados ou por pontes poliênicas ou por pontes mesoiônicas, mantendo inalterados os grupos D e A. As geometrias do estado fundamental das moléculas foram otimizadas com o método AM1, utilizando o programa Mopac93r2. O valor de $\beta(0)$ foi calculado através do método de Hartree-Fock dependente do tempo (TDHF). Nossos resultados indicam que a ponte formada por anéis mesoiônicos pode equivaler a até mais de sete ligações duplas conjugadas, dependendo do anel, e reafirmam que anéis mesoiônicos se constituem em materiais promissores para aplicações em fotônica.
\end{abstract}

In this work we report a semiempirical investigation with the purpose of establishing an equivalence in terms of the value of the first static hyperpolarizability, $\beta(0)$, of push-pull compounds of the type electron-acceptor(A) - bridge - electron-donor(D), either formed by polyenic bridges or by mesoionic bridges, keeping unchanged both $\mathrm{D}$ and A groups. The ground state geometries of the molecules were optimized via AM1 using Mopac93r2 program. The value of $\beta(0)$ was calculated by timedependent Hartree-Fock (TDHF). Our results indicate that a bridge formed by a single mesoionic ring can be equivalent to seven or more conjugated double bonds, depending on the ring, reaffirming that mesoionic rings constitute promising materials for photonics applications.

Keywords: hyperpolarizabilities, polyenes, mesoionic

\section{Introduction}

The synthesis of new organic materials with applications to nonlinear optics has attracted considerable attention from many areas of knowledge, especially from materials science, due to their photoluminescence, conductivity and nonlinear optics properties. The interest in organic materials for nonlinear optics has been stimulated by the expectation of lower cost, faster optical response, higher versatility, possibility of tuning the structure in terms of their nonlinear optical properties, and nonlinear optics susceptibilities comparable or superior to conventional materials. ${ }^{1-6}$

In general, the strategy adopted to intensify the nonlinear optics properties of organic compounds of the type electron acceptor - bridge - electron donor, A-bridge$\mathrm{D}$, consists in varying the electronic asymmetry and the length of conjugated backbone between the electron

\footnotetext{
*e-mail: simas@ufpe.br
}

acceptor (A) and electron donor (D) groups. Marder et al. ${ }^{7}$ synthesized a series of push-pull compounds with polyenic bridges with different A and D groups (Figure 1). Their objectives were the optimization of the bridge length, in terms of the number of conjugated double bonds [n] and also the introduction of new electron donor and acceptor groups that could lead to high experimental values of $\beta(0)$. They analyzed only the cases of $\mathrm{n}=0$ to $\mathrm{n}=3$ for all compounds, except for the $5[\mathrm{n}]$ structure, where $n$ varied from 1 to 4 and for $6[n]$ where $n=1$.

On the other hand, Moura et al. ${ }^{8}$ calculated AM1/TDHF first static hyperpolarizabilities, $\beta(0)$, for these compounds and established the validity of semiempirical predictions for these properties. Moura et al. ${ }^{8}$ found a simple dependence between experimental and calculated $\beta(0)$. Consequently, we can now in principle design new and efficient compounds for nonlinear optics, based on purely theoretical reasonings, via semiempirical calculations. In particular, in that work, we suggested mesoionic rings as a 

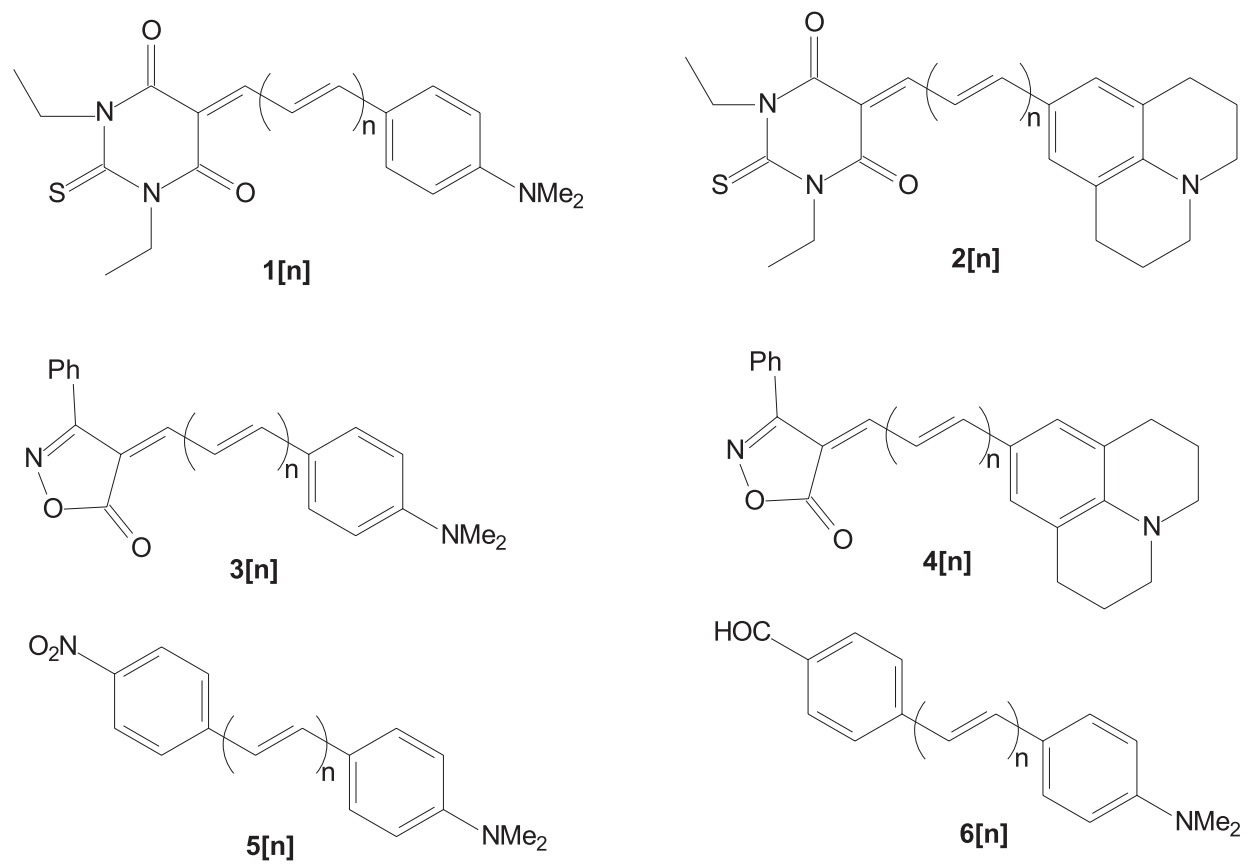

Figure 1. Organic molecules of the push-pull type synthesized by Marder. The structures are represented as $1[\mathrm{n}]$, where 1 stands for the particular pair of electron accepting and electron donor substituent groups, and $\mathrm{n}$ stands for the number of conjugated double bonds.

promising alternative to polyenic bridges in intensifying nonlinear optics properties. ${ }^{8}$

Important questions concerning the structure of mesoionic compounds, in general, can be addressed. de Oliveira et al..$^{9}$ referred to the degree of separation of regions of positive and negative charges, bond orders, electron and charge delocalization, and aromaticity. In that discussion, we have cited some of our X-ray diffration and theoretical studies on mesoionic compounds, from which we concluded that there are regions of positive and negative charges, each presenting both electron and charge delocalizations. Based on this discussion, we introduced a new notation for the structures of mesoionic compounds, Figure 2a, which we believe more accurately represents both the bonding situation and the chemical patterns of reactivity of such compounds. ${ }^{9} 10$

In summary, we have postulated the following definition: mesoionic rings are cyclic dipolar structures in

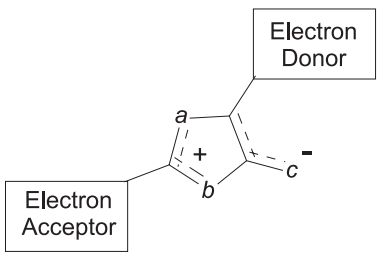

$a, b, c=\mathrm{S}, \mathrm{O}$

(a)

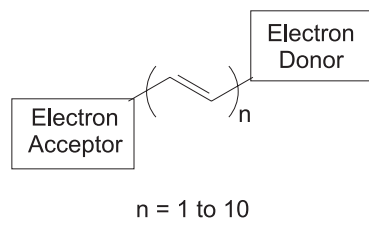

(b)
Figure 2. Structures of push-pull compounds with (a) mesoionic ring bridges generated from varying $\mathrm{O}$ and $\mathrm{S}$ atoms in $a, b$ and $c$ positions and (b) polyenic chain bridges with 1-10 double bonds. which the positive and negative charges are both separated and delocalized within the $\pi$ eletron system. ${ }^{9}$ These compounds, whose basic structure is shown in Figure 2a, are planar five-membered heterocyclic betaines with at least one side-chain, whose $c$-atom is also in the ring plane, and with dipole moments of the order of 5D. Electrons are delocalized over two regions separated by bonds which are essentially single bonds. ${ }^{11}$ One region includes the sidechain atom associated with the HOMO and negative $\pi$-charge and the other region is associated with the LUMO and positive $\pi$-charge. The first excited state of the mesoionic ring represents an electron transfer of one electron from the $\mathrm{p}$ system located at the $\mathrm{HOMO}$ region to the $\pi$ system at the LUMO region, a situation that results in a high dipole moment change upon excitation. These push-pull characteristics generally lead to high hyperpolarizabilities, which can then be further maximized through adequate substitution of electron-donor and electron-acceptor groups. Being organic molecules, mesoionic compounds can be further modified in order to enchance their intrinsic separation of charges.

To corroborate our theoretical findings, we have been designing and synthesizing mesoionic compounds to be useful as promising materials for nonlinear optics with the following rings: 1,3 -dithiolium-4-thiolate, ${ }^{12,13,9} 1,3,4$ thiadiazolium-2-phenylaminide,,$^{14}$ 1,2,4-triazolium-3thiolate, ${ }^{15}$ 1,2,4-oxadiazoles, ${ }^{16,17}$ 1,3,4-triazolium-2selenolates, ${ }^{18} 1,3$-thiazolium-5-thiolates. ${ }^{19-21}$

Furthermore, we have also measured the nonlinear 
optics properties of these mesoionic compounds through experimental techniques: Z-scan (which allows the determination of the nonlinear refractive index, $\mathrm{n}_{2}$, from which one can infer values for the second hyperpolarizability $\gamma$, a microscopic property related to nonlinear third order process), and optical Kerr gate (which allows one to investigate the dynamics of third-order processes)..$^{22}$

The trends displayed by our experimental values agree with the AM1-TDHF predictions and may be understood qualitatively in terms of a two-level system. The optical gate experiments, in which we used Kerr's effect, revealed that the response time for these mesoionic compounds are less than $60 \mathrm{fs}$ at $800 \mathrm{~nm}$. The largest measured value of $\beta(0)$ we obtained for the 3-methyl-2-(p-chlorophenyl)-4( $p$-isopropylphenyl)-1,3-thiazolium-5-thiolate mesoionic was $349\left(10^{-30} \mathrm{esu}\right){ }^{23}$ which is only 2.6 times less than one of the largest values ever reported. ${ }^{7}$ For another of our compounds, 4-phenyl-2-( $p$-chlorophenyl)-1,3-oxazolium5 -olate mesoionic, we obtained an experimental value for $\gamma$ of $24.2\left(10^{-32} \mathrm{esu}\right)$, which is also similar to the highest reported ones. ${ }^{24}$

More recently, we have also carried out some studies on intensity dependent transmission and laser-induced fluorescence in liquid solutions of some mesoionic systems. ${ }^{25,}{ }^{26}$ These properties were observed when the solutions were pumped with nanosecond lasers operating at 1064,604 , and $570 \mathrm{~nm}$. Our results indicate that twophoton absorption (TPA) is the dominant mechanism which causes the observed behavior. The TPA cross-sections measured have values ranging from $0.33 \times 10^{-20} \mathrm{~cm}^{4} / \mathrm{GW}$ to $0.43 \times 10^{-18} \mathrm{~cm}^{4} / \mathrm{GW}^{27}$

In this work, as part of a complete theoretical investigation of the nonlinear optics properties of molecular systems with charge transfer, we attempt to establish an equivalence, in terms of calculated first static hyperpolarizabilities, $\beta(0)$, between compounds with polyenic bridges (Figure $2 \mathrm{~b}$ ) and compounds with mesoionic rings (Figure 2a), maintaining unchanged, for both cases, the electron-donor and electron-acceptor groups. Accordingly, we intend to answer the following question: for a given pair of $\mathrm{A}$ and $\mathrm{D}$ substituents, which size of polyenic bridge possesses a value of $\beta(0)$ equivalent to the value of the compound with a mesoionic bridge?

\section{Methodology}

In this work, we considered polyenic bridges with one up to ten double bonds and also considered eight different types of mesoionic rings (Figure 3), totaling 48 different calculated mesoionic compounds.

These mesoionics rings were generated from the variation of atoms $\mathrm{O}$ or $\mathrm{S}$ in positions, $a, b$ and $c$ of Figure $2 \mathrm{a}$, resulting in the following rings (Figure 3): 1,3dithiolium-5-thiolates (SSS), 1,3-dithiolium-4-olates (SSO), 1,3-oxathiolium-5-olates (SOO), 1,3-oxathiolium4-olates (OSO), 1,3-dioxolium-4-olates (OOO), 1,3oxathiolium-4-tiolates (OSS), 1, 3-oxathiolium-5-tiolates (SOS) and 1,3-dioxolium-4-tiolates (OOS). The symbols inside the parenthesis indicate, for example, that the described mesoionic (SSS), has sulfur atoms in positions $a, b$ and $c$. The adopted methodology consisted of two steps: $(i)$ the ground state geometries for all molecules were optimized with the semiempirical method AM1 implemented in MOPAC 93r2 program, ${ }^{28}$ and (ii) the value of $\beta(0)$ was calculated through method TDHF, also implemented in this program.

The MOPAC keywords used in all geometry optimizations were: GNORM=0.01 (in order to guarantee the energy minimum), SCFCRT=1.D-8 (in order to increase the SCF convergence criteria) and XYZ (the geometry optimizations were performed in Cartesian coordinates). For the static hyperpolarizability calculations we used:

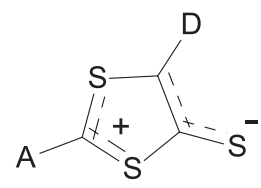

(SSS)<smiles>[Y]c1oc([O-])c([2H])[o+]1</smiles>

(OOO)

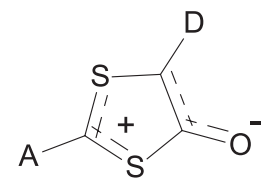

(SSO)<smiles>[Y]c1oc([O-])c([2H])[s+]1</smiles>

(OSS)<smiles>[Y]c1oc([O-])c([2H])[s+]1</smiles>

(SOO)<smiles>[Y]C1=[O+]C(=[S-])C([2H])=[S+]1</smiles>

(SOS)<smiles></smiles>

(OSO)<smiles>[Y]c1oc([S-])c([2H])[o+]1</smiles>

(OOS)

Figure 3. Structures of the mesoionic rings considered, where A and D stand for electron-donor and electron-acceptor substituent groups, respectively. 
$\operatorname{POLAR}(\mathrm{E}=(0.0), \mathrm{BETA}=1, \mathrm{IWFLB}=0, \mathrm{TOL}=1 . \mathrm{D}-$ 9,BTOL=1.D-9).

\section{Results and Discussion}

Table 1 shows the higher AM1-TDHF $\downarrow \beta(0) \downarrow$ values for the bridged double bond compounds $(n=10)$ and for the 48 studied mesoionic compounds.

In this table, structure 2[10] means that the electron donating group is a julolidinyl and the electron receptor group is the $N, N^{\prime}$-diethylthiobarbituric acid and the molecule has ten double bonds in the polyenic bridge. The corresponding mesoionic compounds are listed in the columns. For example, the SSS in the 2[10] row, means: the ring where $a, b$ and $c$ are all $\mathrm{S}$, with the same substituent groups D and A of compound 2[10].

The highest calculated $\beta(0)$ value was $387 \times 10^{-30} \mathrm{esu}$ for the mesoionic compound with (OOS) ring and $\mathrm{A}=$ $N, N$ '-diethylthiobarbituric acid and $\mathrm{D}=$ julolidinyl groups, equivalent to a $2[n]$ structure.

From previous papers, ${ }^{8}$ we know that the presence of D and $\mathrm{A}$ groups connected to the mesoionic ring in the correct locations produces an increase in $\beta(0)$. These positions are (see Figure 2): the right side (negative part) of the mesoionic ring for an electron-donor group $\mathrm{D}$, and the left side (positive part) of the mesoionic ring for an electronaccepting group A. Indeed, the right part of the mesoionic ring is an electron rich region and is associated with the HOMO, and the presence of an electron donor substituent group increases $\beta(0)$. Likewise, the left part of the ring has an electron deficient character and is associated with the LUMO. Thus, $\beta(0)$ can be intensified via the presence of an electron withdrawal group in this position.

We observed that the substitution of a sulphur atom by an oxygen atom in a mesoionic ring increases $\beta(0)$. This occurs for all calculated mesoionic compounds, even for molecules with different $\mathrm{D}$ and $\mathrm{A}$ groups and mainly oxygen atoms located at $a$ and $b$ positions. In contrast, when the oxygen atom is located in the side chain $(c=\mathrm{O})$, as, for example, (SSO) mesoionic ring, we have found $\beta(0)=$ $69 \times 10^{-30} \mathrm{esu}$, that is the lowest calculated $\beta(0)$ for all mesoionic compounds (Table 1, entry 6). Even so, this quantity is equivalent to a $\beta(0)$ for a molecule with a polyenic bridge of approximately four to five double bonds, as in structure 6[n] (Figure 4). The 6[n] structure has $\mathrm{D}=(\mathrm{Me}){ }_{2} \mathrm{~N}-\mathrm{C}_{6} \mathrm{H}_{4}$ and $\mathrm{A}=\mathrm{HOC}-\mathrm{C}_{6} \mathrm{H}_{4}$.

From our results, we are capable of pointing out the best mesoionic ring in terms of computed AM1/TDHF $\beta(0)$ : the (OOS) ring. The only exception is the $1[\mathrm{n}]$ structure, where the highest calculated $\beta(0)$ was, instead, for the (OOO) mesoionic ring. From these findings, we can suggest that, for the studied compounds, when a sulfur atom is located at the exocyclic position and $a, b=\mathrm{O}$, we have an intensification of the calculated $\beta(0)$ values.

Comparing the calculated $\beta(0)$ for each mesoionic compound, we can notice the number of double bonds in a polyenic bridge that would be necessary, in order for it to be equivalent to a maximum calculated $\beta(0)$ value of a mesoionic ring. For example, for mesoionic compounds with SSS ring and groups D and A equal to the structure 2[n], the calculated $\beta(0)$ was $191 \times 10^{-30}$ esu. This way, by interpolation, five conjugated double bonds would be necessary in the polyenic bridge, where $\beta(0)=198 \times 10^{-30} \mathrm{esu}$. Another case is for mesoionic compounds with OOS ring and same groups $\mathrm{D}$ and $\mathrm{A}$. The calculated $\beta(0)=387 \times 10^{-30} \mathrm{esu}$, and it would be necessary more than ten double bonds in a polyenic bridge, since the higher calculated $\beta(0)$ for the compound with ten double bonds is $271 \times 10^{-30}$ esu. For the system 1,3-dithiolium-5-tiolates ( $a, b$ and $c=\mathrm{S}$ ) with the groups $\mathrm{D}=p-\mathrm{C}_{6} \mathrm{H}_{4}-\mathrm{N}(\mathrm{Me})_{2}$ and $\mathrm{A}=N$ ', $N$-diethylthyobarbituric, the calculated $\beta(0)$ is $174 \times 10^{-30} \mathrm{esu}$, while the corresponding similar $\beta(0)$ value, for a polyene system with seven dienic units is $\beta(0)=167 \times 10^{-30}$ esu.

In order to answer our initial question, we can point out that, in average, considering our highest calculated $\beta(0)$ for the OOS ring, it is necessary for a polyenic bridge

Table 1. $\beta(0)$ values in $10^{-30}$ esu for push-pull compounds with either polyenic (up to ten double bonds), or mesoionic ring bridges

\begin{tabular}{cccccccccc}
\hline \multirow{2}{*}{$\begin{array}{c}\text { Pntry } \\
\end{array}$} & \multicolumn{7}{c}{ Melyenic Bridges } \\
& $(\mathrm{n}=10)$ & $(S S S)$ & $($ SSO $)$ & $($ SOO $)$ & $($ OSO $)$ & $($ OOO $)$ & $($ OSS $)$ & $($ SOS $)$ & $($ OOS $)$ \\
\hline 1 & 249 & 174 & 71 & 190 & 161 & 321 & 198 & 182 & 299 \\
2 & 271 & 191 & 100 & 245 & 181 & 377 & 224 & 224 & 387 \\
3 & 205 & 134 & 95 & 180 & 176 & 250 & 187 & 178 & 265 \\
4 & 220 & 150 & 142 & 206 & 207 & 290 & 203 & 202 & 299 \\
5 & 152 & 102 & 97 & 158 & 148 & 172 & 156 & 163 & 185 \\
6 & 102 & 82 & 69 & 122 & 113 & 120 & 121 & 128 & 128 \\
\hline
\end{tabular}

Notation: The entries are related to groups A and D in Figure 1. e.g.: for entry 2 we have as electron donating group julolidinyl, and as the electron withdrawal group $N, N^{\prime}$-diethylthiobarbituric acid. In this case, for the polyenic bridge with ten double bonds the $\beta(0)$ value is $271 \times 10^{-30}$ esu, whereas for the equivalent compound with the mesoionic ring (OOS), Figure 2 , we have for $\beta(0)$ the value of $387 \times 10^{-30}$ esu (for the same groups $\mathrm{A}$ and D). 
to possess from seven up to ten double bonds to be equivalent, in terms of $\beta(0)$, to a compound containing a mesoionic ring. This fact places us in position to invest in the synthesis of these mesoionic compounds for application in nonlinear optics, since the synthesis of a system that has ten conjugated double bonds may often become difficult. ${ }^{29-32}$

Figure 4 shows the graphs of the dependence of the value of $\beta(0)$ with the number of double bonds in the polyenic bridges for each type of structure considered.

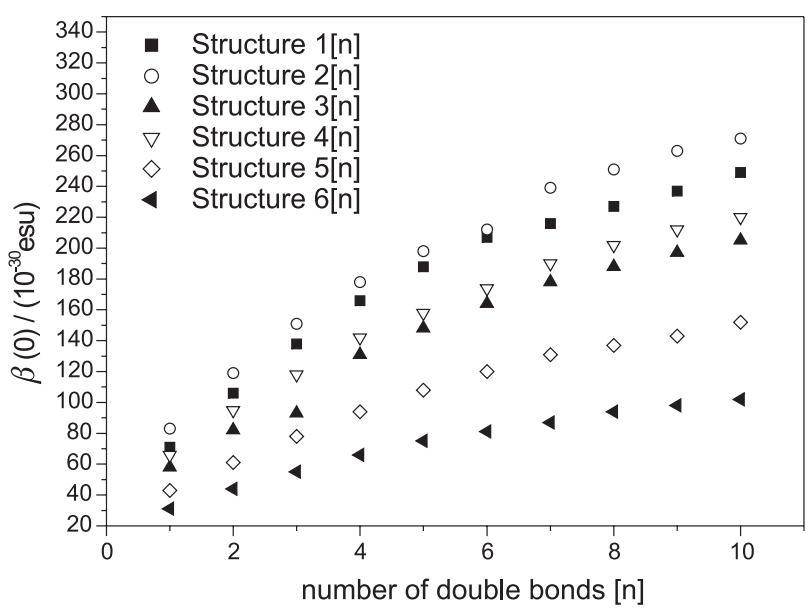

Figure 4. Values of the first static hyperpolarizability, $\beta(0) /\left(10^{-30}\right.$ esu), calculated by AM1/TDHF method as function of the number of double bonds $[\mathrm{n}]$ in the conjugated polyenic bridge.

Indeed, for all cases, there exists an increase in the value of $\beta(0)$ with the number of double bonds in the polyenic chain. However, when we reach a critical number of double bonds, a saturation of the trend occurs in $\beta(0)$. This adds evidence, justifying our work in the synthesis of compounds containing mesoionic rings.

\section{Conclusions}

Our results indicate that the predicted AM1/TDHF $\beta(0)$ for compounds with mesoionic rings is equivalent to compounds with approximately seven, sometimes even ten, conjugated double bonds for a series formed by compounds structured with Marder's substituents. For these, we are now in position of suggesting that mesoionic rings are more efficient bridges than polyenes for the design of materials for nonlinear optics.

\section{Acknowledgments}

Financial support from CNPq, CNPq-PROFIX, CAPES (Brazilian agencies), and Instituto do Milênio de Materiais Complexos is gratefully acknowledged. We also thank
CENAPAD (Centro Nacional de Processamento de Alto Desempenho) at Campinas, Brazil, for having made available to us their computational facilities.

\section{References}

1. Brédas, J. L.; Adant, C.; Tackx, P.; Persoons, A.; Chem. Rev. 1994, 94, 243.

2. Maya, E. M.; Garcia-Frutos, E. M.; Vázquez, P.; Torres, T.; Martín,G.; Rojo, G.; Agulló-López, F.; González-Jonte, R. H.; Ferro, V. R.; de La Vega, J. M. G.; Ledoux, I.; Zyss, J.; J. Phys. Chem. A 2003, 107, 2110.

3. Prasad, P. N.; Williams, D. J.; Introduction to Nonlinear Optical Effects in Molecules and Polymers; John Wiley and Sons: New York, 1991, ch. 7.

4. Tykwinski, R. R.; Gubler, U.; Martin, R. E.; Diederich, F.; Bosshard, C.; Gunter, P.; J. Phys. Chem. B 102 1998, 4451.

5. Kanis, D. R.; Ratner, M.A.; Marks, T. J.; Chem. Rev. 1994, 94 , 195.

6. Chemla, D. S.; Zyss, J., eds.; Nonlinear Optical Properties of Organic Molecules and Crystal, Academic Press: Orlando, 1987, vols. 1-2.

7. Marder, S. R.; Cheng, L.T; Tiemann, B. G.; Friedli, A. C.; Blanchard-Desce, M.; Perry, J. W.; Skindhoj, J.; Science 1994, 263,511

8. Moura, G. L. C.; Simas, A. M.; Miller, J.; Chem. Phys. Lett. 1996, 257, 639 .

9. de Oliveira, M. B.; Miller, J.; Pereira, A. B.; Galembeck, S. E.; Moura, G. L. C.; Simas, A. M.; Phosphorus, Sulfur, Silicon Relat. Elem. 1996, 108, 75.

10. de Athayde-Filho, P. F.; Miller, J.; Simas, A. M.; SynthesisStuttgart 2000, 11, 1565.

11. Simas, A. M.; Miller, J.; de Athayde-Filho, P. F.; Can. J. Chem. 1998, 76, 869 .

12. Cheung, K. K.; Galembeck, S.; Miller, J.; de Oliveira, M. B.; Pereira, A. B.; Simas, A. M.; Acta Crystallogr. C 1991, 47, 2630.

13. Cheung, K. K.; Galembeck, S.; Miller, J.; de Oliveira, M. B.; Pereira, A. B.; Simas, A. M.; Acta Crystallogr. C 1992, 48, 523.

14. Cheung, K. K.; Echevarria, A.; Galembeck, S.; Aparecida, M.; Maciel, M.; Miller, J.; Rumjanek, V. M.; Simas, A. M.; Acta Crystallogr. C 1992, 48, 1471.

15. Cheung, K. K.; Echevarria, A.; Galembeck, S.; Maciel, M.; Miller, J.; Rumjanek, V. M.; Simas, A. M.; Acta Crystallogr. C 1993, 49, 1092.

16. Srivastava, R. M.; de Morais, L. P. F.; Catanho, M.T. J. A.; de Souza, G. M. L.; Seabra, G. M.; Simas, A. M.; Rodrigues, M. A. L.; Heterocycl. Commun. 2000, 6, 41.

17. Carpenter, G. B.; Ventura, E.; de Morais, L. P. F.; Srivastava, R. M.; Simas, A. M.; Faure, R.; J. Mol. Struct. 2001, 561, 29. 
18. de Athayde-Filho, P. F.; Simas, A. M.; Gonçalves, S. M. C.; Miller, J.; Phosphorus, Sulfur, Silicon Relat. Elem. 2000, 161, 115.

19. Lira, B. F.; de Athayde-Filho, P. F.; Miller, J.; Simas, A. M.; Dias, A. D.; Vieira, M. J.; Molecules 2002, 7, 791.

20. de Athayde-Filho, P. F.; Miller, J.; Simas, A. M.; Lira, B. F.; Luis, J. A. D.; Zuckerman-Schpector, J.; Synthesis-Stuttgart 2003, 5, 685 .

21. de Athayde-Filho, P. F.; Ph.D. Thesis, Universidade Federal de Pernambuco, Recife, Brazil, 1999.

22. Bezerra, A. G.; Gomes, A. S. L.; de Athayde-Filho, P. F.; da Rocha, G. B.; Miller, J.; Simas; A. M.; Chem. Phys. Lett. 1999, 309, 421.

23. Bezerra Jr., A. G.; Ph.D. Thesis, Universidade Federal de Pernambuco, Recife, Brazil, 1999.

24. Marder, S. R.; Torruellas, W. E.; Blanchard-Desce, M.; Ricci, V.; Stegeman, G. I.; Gilmour, S.; Brédas, J. L.; Li, J.; Bublitz, G. U.; Boxer, S. G.; Science 1997, 276, 1233.

25. Rakov, N.; de Araujo, C. B.; Rocha, G. B.; Simas, A. M., Athayde-Filho, P. A. F.; Miller, J.; Appl. Optics 2001, 40, 1389.
26. Menezes, L. S.; de Araujo, C. B.; Alencar, M. A. R. C.; de Athayde-Filho, P. F.; Miller, J.; Simas, A. M.; Chem. Phys. Lett. 2001, 347, 163.

27. Rakov, N.; de Araujo, C. B.; Rocha, G. B.; Simas, A. M.; de Athayde-Filho, P. F.; Miller, J.; Chem. Phys. Lett. 2000, 332, 13.

28. Stewart, J.P.; MOРАC 93.00 Manual, Fujitsu: Tokyo, Japan, 1993.

29. Babudri, F.; Cicciomessere, A. R.; Farinola, G. M.; Fiandanese, V.; Marchese, G.; Musio, R.; Naso, F.; Sciacovelli, O.; J. Org. Chem. 1997, 62, 3291.

30. Patro, B.; Ila, H.; Junjappa, H.; Tetrahedron Lett. 1992, 33, 809.

31. Williams, J. M.; McGarvey, G. J.; Tetrahedron Lett. 1985, 26, 4891.

32. Stewart, S. K.; Whiting, A.; Tetrahedron Lett. 1995, 36, 3925.

Received: October 10, 2003 Published on the web: March 9, 2005 